\title{
Comments on Professor Raymond Barre's Lecture
}

\author{
by J. David Cummins *
}

Mr. Barre is concerned about the increasing demand for economic security and about the portion of that demand that will be satisfied by the private as opposed to the public sector. This is an issue of critical importance in the United States due to stagnating real incomes and the difficulties faced by the social security system. My comments are addressed to the interactions between the public and private sectors in the provision of economic security.

\section{Scope of economic security}

Economic security in modern industrialized societies is provided through a wide range of social and economic arrangements. A distinguishing feature of many of these arrangements is the reduction of the risk of financial hardship or loss. It is helpful to subdivide such risks into two categories - individual risks and collective risks. ${ }^{1}$ The former risks are more or less independent across economic agents. Examples include the risk of death and the risk of a fire or automobile accident. Collective risk, on the other hand, affects all economic agents, although in different degrees. The risk posed by inflation is an important collective risk mentioned by Mr. Barre.

The difference between individual and collective risk can be characterized by considering the following simple model :

$$
\ell_{i t}=\sum_{j} x_{i j t}+\beta_{i} y_{t}
$$

where $\ell_{i t}=$ the total losses sustained by individual $i$ in period $t$,

$x_{i j t}=$ total losses of type $j$ suffered by individual $i$ in period $t$ due to individual risk,

$y_{t}=$ losses sustained by society during period $t$ due to collective risk (for simplicity, it is assumed that only one type of collective risk is present or, equivalently, that collective risk can be treated as a composite), and

$\beta_{i}=\mathrm{a}$ coefficient indicating the effect of collective losses on individual $i$.

* Professor of Insurance and Associate Director of the S.S. Huebner Foundation, both at the Wharton School, University of Pennsylvania.

1 The concepts of individual and collective risks are similar to C. A. Kulp's concepts of fundamental and particular risks. See Houston [5, p. 516]. 
Losses due to individual and collective risks can be considered over two dimensions - losses across economic agents within a specified time period and losses sustained by economic agents and/or society as a whole across time. Within any given time period, an important distinction between individual and collective risk is that the former can be reduced through diversification, while the latter cannot. In perfect insurance markets, individual $i$ can replace each $x_{i j t}$ with its expected value by purchasing insurance. In this case, losses become :

$$
\bar{\ell}_{i t}=\sum_{j}\left(1+\pi_{j}\right) \bar{x}_{i j t}+\beta_{i} y_{t}
$$

where $\bar{x}_{i j t}=$ the expected value of $x_{i j,}$, and

$\pi_{j}=$ the loading of the insurance pool for a loss of type $j$ (for premiums of different risks).

Insurance thus permits individuals to exchange uncertain (and potentially large) losses for certain small losses. If insurance transactions are costless, $\pi_{j}=0$, for all $j$. Under these circumstances, utility theory tells us that all risk-averse consumers will insure.

The total loss sustained by society during time period $t$ due to individual risk is equal to $\sum_{i} \sum_{j} x_{i j t}$. Insurance does not change the amount of this loss but rather redistributes it. ${ }^{2}$ Although in a large group (such as society as a whole) the ith individual's share of this total will tend to be close to $\sum_{j} \bar{x}_{i j t}$, it will not generally equal this amount precisely due to random fluctuations. Hence, diversification across economic agents does not totally eliminate individual risk. Real world reflections of this fact are the payment of policyholder dividends and (more rarely) the collection of assessments. The remaining risk can be further reduced by diversifying across time. For example, an insurance company can accumulate funds during periods when losses are relatively low to help pay claims in periods when losses are high. This tends to smooth fluctuations in premiums and thus reduces risk by making the policyholders' costs more predictable.

Within a given period, collective risk cannot be reduced by diversification no matter how many economic agents are present in society. Hence, insurance is not helpful in dealing with this type of risk. The best that can be done is to attempt to reduce collective risk through some type of collective action. For example, governments can adopt economic policies designed to reduce inflation. It is also possible to mitigate the consequences of collective risks by spreading losses over time. For example, the government may borrow to provide disaster relief and repay the loans out of taxes in subsequent periods. Thus, collective risk is subject to a degree of inter-temporal diversification.

Government provision of economic security enters the picture in two additional ways. First, the private markets for some types of risks may not function properly leaving the demand for economic security in these markets unfulfilled. Government then may intervene either directly or in a regulatory capacity to restore or substitute for the operation of the market. Second, the allocation of goods and services implicit in private markets may be considered socially or politically unacceptable, and govern-

2 This statement applies only as an approximation. In reality, the frequency or severity of loss may be affected by the existence of insurance. This phenomenon is known as moral hazard. 
ment may take action to change this distribution. The latter type of intervention does not really reduce risk, but it may change the price at which risk reduction can be purchased. In the United States, government substitutes directly for the market in the provision of flood insurance, and provides subsidies for certain types of drivers through automobile insurance assigned risk plans.

\section{Risk sharing and private incentives}

In the context of the model specified above, Mr. Barre has two major concerns : (1) increases in the number and types of risk borne through the public sector; and (2) increases in the degree of subsidization across groups for both individual and collective risks. The fear is that such increases will limit personal freedom and hinder economic development.

The growth of economic security programs is determined by society's demands for security as reflected in the economic and political process. Most would agree that every individual is entitled at least to a subsistence income and to nondiscriminatory treatment by society. Both the definition of subsistence and the amount of entitlement above subsistence are important political issues mentioned by $\mathrm{Mr}$. Barre. Clearly, the Reagan administration and the current government of France have widely differing views on this topic. Unlike Mr. Barre, I am not convinced that the demand for economic security is increasing, at least in the United States. Rather, it may have leveled off after increasing steadily for a number of years. Another question is whether this demand is being correctly interpreted through the political process.

Once it is clear that a particular type of economic security is to be supported by society, the question becomes how best to provide it. In considering this issue, several economic criteria should be employed, including the following :

1. Efficiency. Efficiency is defined as the degree to which a program satisfies individual demands for the type of economic security under consideration. A program can be inefficient by providing too much security to some groups and/or too little to others. For example, a social security program may provide redundant benefits for wealthy individuals and at the same time provide inadequate benefits to those in the lowest economic brackets. Obviously, both types of inefficiency should be avoided if possible.

2. Costs of operation. Economic security programs have the goal of redistributing resources among members of society. To conserve resources, it is important that as little as possible of the funds transferred be absorbed by the allocation mechanism. In the United States, society has chosen to provide tax incentives for the provision of group life insurance but not individual life insurance. One justification for this is that individual life insurance involves very high distribution costs, while group life insurance is relatively inexpensive to distribute.

3. Incentives and disincentives. In addition to their benefits, economic security programs can create disincentives with damaging economic consequences. One such problem is moral hazard, which involves increases in the frequency or severity of loss 
because of the existence of the economic security program. Moral hazard represents a net loss to society. An example is the lengthening of hospital stays without medical justification because of the existence of hospitalization insurance. ${ }^{3}$ Some programs are more susceptible to moral hazard than others; and, as Mr. Barre points out, program design features such as coinsurance and deductibles can be used to reduce the problem. Economic security programs also can create incentives for beneficial activities, as when fire insurance premium discounts are given for the installation of sprinkler systems.

4. Externalities. Besides their effects on the recipient and providers of economic security, these programs can have effects on other areas of economic activity. One important example is the potential impact of social security on private saving and hence on capital formation. 4 This issue, which has been extensively debated, has implications for the relative support to be given to public as opposed to private pensions.

\section{Forms of government intervention}

If the provision of security by private markets is deemed inadequate, government may intervene in an attempt to bring about improvements. This intervention can take one of several forms, and the choice of an intervention method generally should hinge on the criteria outlined above. The three principal forms of intervention are the following : (1) direct provision of insurance by the government, (2) tax subsidization or other types of incentives to encourage private sector action, and (3) regulation to improve the operation of private markets.

An example of the first approach is the social security system in the United States. It is characterized by mandatory participation and an emphasis on higher relative benefits for those in the lower income brackets. The system is viewed by most as essential to meet the needs for subsistence income. However, some believe that it has moved too extensively into the provision of security for those in the higher income brackets. Such coverage probably could be provided more efficiently through the private sector. As already mentioned, the system also may have deleterious effects on private capital formation.

Tax subsidization is the method chosen to encourage the provision of private pension plans, group life and health insurance, and other employee benefit programs in the U.S. These programs probably are more efficient than social security because employees to some extent can choose an employer with a benefits program suited to their tastes. Employee benefits programs are likely to become more efficient in the future as flexible benefit plans are adopted which permit employees of a given employer to select their own mix of benefits. Private pension plans may have a positive impact on capital formation, although their net effect has not been definitely established. ${ }^{5}$ In any event, they are very likely superior to social security in this regard.

3 See Donabedian [4].

4 See Munnell [8].

5 This issue is discussed in Waters [10]. 
In theory, employee benefits plans are less efficient than individual insurance, which can potentially be tailored precisely to the needs of the individual. However, they may be preferable to individual insurance because their administrative and marketing costs are, relatively, much lower. This stems from economies of scale both in administration and in information. The latter effect arises because it is cost effective for a business firm to acquire the information necessary to bargain effectively with insurers. For the individual, on the other hand, such information is difficult and costly to obtain. Hence, individual markets generally are less subject to the discipline of competition and absorb more of the economic security dollar in administrative and marketing expenses.

The final method of intervention is through regulation. This approach can be used to correct problems in existing markets or to restore markets that have failed. A good example of appropriate regulation in the economic security field would be government action to require the distribution of meaningful price information in the individual life insurance market. ${ }^{6}$ This would permit consumers to make more rational choices and hence lessen the pressure for additional economic security expenditures at the firm and governmental levels. Regulation is in many cases the least expensive form of government intervention. It is not without problems, however, as some have hypothesized that the regulatory agency eventually serves the interests of the regulated industry rather than those of the consumer. ${ }^{7}$

\section{Public and private programs in the U.S.}

A rough indication of the relative importance of public and private economic security programs in the United States is provided in table 1, which indicates the payments into some important public and private programs in the U.S. in 1977. The table also gives an approximation to the tax subsidy provided to the private programs. The focus of the table is on social security and comparable private programs; other programs such as workers' compensation which offer similar benefits are not included in this analysis. The table indicates only the employers', not the employees', contributions into employer-provided programs.

Private economic security programs provided by employers include retirement and employee benefits plans. In general, contributions to retirement plans are deductible by employers in computing taxable income. ${ }^{8}$ Neither the employers' contributions nor the investment earnings on retirement funds are taxable to employees prior to retirement. After retirement, pension benefits generally are taxable income to employees. Employer

6 Federal Trade Commission [9].

7 This is referred to as the Stigler hypothesis. It has been investigated by Ippolito [7] with respect to automobile insurance regulation in the United States. He found no support for the hypothesis but did find other distortions due to regulation.

8 The comments in this paper about the tax treatment of benefit programs are intended to give a general overview of this topic. The actual details are quite complex and exceptions to every generalization exist. More information is available in sources such as Allen, Melone, and Rosenbloom [1]. 
Table 1 : Payments into Selected Public and Private Old Age, Survivors, and Disability Programs in the United States : 1977

(Millions of dollars)

Contributions, Taxes

Program and/or Premiums

I. Social Security $a$

Old Age \& Survivors Insurance

$\$ 70,183$

9,776

Disability Insurance

14,466

Health Insurance $b$

$\$ 94,425$

Total

II. Private Programs $c$

Provided by Employers (employers' contrib. only)

Corporate Plans: Retirement

36,464

Employee Benefit

23,498

Partnership \& Sole Proprietorship Plans :

Retirement
Employee Benefit

393

658

Total

61,013

Individual Plans

Health Insurance $d$

5,025

Life Insurance (ordinary and industrial)

Annuities $e$

$\frac{4,552}{35,037}$

Total

Total Private Programs

96,050

III. Estimated Private Plan Tax Subsidy $f$

$a$ Approximation to calendar year $1977=.75^{\circ} \times$ figure for fiscal year $1977+.25 \times$ figure for fiscal year 1978 .

$b$ Medicare only.

$c$ Excludes coverages such as workers' compensation and automobile insurance which provide some survivorship and health benefits.

$d$ Income tax deductible component $=\$ 1,715$.

$e$ This item may overlap to some extent with retirement contributions by employers. Data were not available to measure the extent of this overlap.

$f$ Computed by multiplying average tax rate in 1977 for returns which indicated a positive tax for taxpayers earning $\$ 15,000$ or more (.171) by total employer contributions and premiums $(\$ 61,013)$ and the deductible portion of individual health insurance premiums $(\$ 1,715)$. From this amount is deducted an estimate of the taxes paid on retirement benefits $(\$ 2,327)$. No adjustment has been made for the taxability of employer contributions for large amounts of group life insurance.

Sources: Social security section, Social Security Bulletin 43, no. 4 (April 1980). Life insurance and annuity data are from Life Insurance Fact Book - 1979 (Washington, D.C.: American Council of Life Insurance, 1979). All other data are from Internal Revenue Service, Statistics of Income - 1977, Corporation Income Tax Returns (Washington, D.C.: U.S. Government Printing Office, 1981) ; Internal Revenue Service, Individual Income Tax Returns (Washington, D.C., 1980); and Internal Revenue Service, Business Income Tax Returns, preliminary edition (Washington, D.C., 1979). 
contributions to benefit plans such as group life and health insurance are deductible by employers and, except for group life insurance above a threshold face value, not taxable income to employees. Benefit payments from these plans typically are tax-free to employees.

Individual health insurance premiums are partially deductible, but in the aggregate the deduction is far less than half the premiums paid. Individual life insurance premiums must be paid from after-tax income. The interest earnings credited to policyholders by life insurers generally are not taxed to policyholders. An unknown proportion of the contributions for individual annuities listed in the table are subject to tax deferral under the individual retirement account (IRA) provisions of the federal Internal Revenue Code.

The table indicates that the payments into the selected private economic security programs in 1977 ( $\$ 96$ billion) were roughly of the same magnitude as contributions to social security ( $\$ 94.4$ billion). The approximate amount of tax subsidy to these private programs in the same year is $\$ 8.4$ billion. This estimate is based on the assumption that employers would still be able to deduct contributions to benefit plans and would not change the amount contributed if certain tax benefits were eliminated. In particular, the subsidy calculations assume that employees would have to declare the employers' contributions as taxable income. Due to data limitations, the $\$ 8.4$ billion does not include the tax subsidies for investment earnings on pension plans and individual life insurance. The addition of these items probably would increase the subsidy by more than 50 percent. ${ }^{9}$ Although these estimates are not precise due to data limitations, they do give an indication of the magnitude of the subsidy and probably are conservative.

Policymakers should give more attention to the magnitude and relative advantages of tax subsidies in determining future public policy in this field. It may be more effective to finance economic security benefits in this way rather than through government programs. However, care should be taken not to overallocate or underallocate resources to such benefits through tax subsidies that are too high or too low.

\section{Conclusion}

Mr. Barre has identified some very important dangers inherent in the expansion of economic security programs. One way to avoid or minimize such problems while meeting the demand for economic security is through well-designed programs that rely to the greatest extent possible on private market mechanisms. Such programs are not always feasible, but an imaginative attempt to provide them may be our best path to continued economic well-being.

9 Based on rough calculations using data from American Council of Life Insurance [2] and [3]. The life insurance calculations apply the Menge formula to aggregate data, while the pension plan calculations are the product of plan assets in 1977 and an assumed yield rate. (The Menge formula, which is used to calculate deductible interest earnings for life insurers for federal income tax purposes, is discussed in Huebner and Black [6, pp. 677-681].) An attempt was made to use assumptions which would lead to the estimation of a lower bound for the subsidy. 


\section{REFERENCES}

1. ALlen, E. T., MElone, J. J., and ROSEnblooM, J.S. : Pension Planning, Irwin, Homewood (IIl.), 1981.

2. AMERICAN COUNCIL OF LIFE INSURANCE : Life Insurance Fact Book - 1979, Washington, D.C., 1979.

3. AMERICAN COUNCIL OF LIFE INSURANCE: Pension Facts - 1978-1979, Washington, D.C., 1979.

4. DONABEDIAN, A.: Benefits in Medical Care Programs, Harvard University Press, Cambridge (Mass.), 1976.

5. HOUSTON, D. B. : "Risk, insurance, and sampling”, Journal of Risk and Insurance, 31 (December 1964), 511-538.

6. HUEBNER, S. S., and BLACK, K. Jr. : Life Insurance, Prentice-Hall, Englewood Cliffs (N.J.), 1982.

7. IPPOLITO, R. A. : "Effects of price regulation in the automobile insurance industry", Journal of Law and Economics, 22 (1979), 55-89.

8. MUNNEL, A. H. : The Effect of Social Security on Personal Saving, Ballinger, Cambridge (Mass.), 1974.

9. UNITED STATES, FEDERAL TRADE COMMISSION : Life Insurance Cost Disclosure, U.S. Government Printing Office, Washington, D.C., 1979.

10. WATERS, W. R.: Employer Pension Plan Membership and Household Wealth, Irwin, Homewood (III.), 1981. 